\title{
Eficacia del número, según San Agustín
}

\begin{abstract}
Ea potentia qua fortiter a fine usque ad finem attingit (Deus), numerus fortasse dicitur; ea vero qua disponit omnia suaviter, sapientia proprie jam vocatur; cum sit utrumque unius ejusdemque sapientiae... Dedit numeros omnibus rebus... Sapere autem non dedit corporibus, neque animis omnibus, sed tantum rationalibus (De libero Arbitrio, II, 11, 31 PL. 32, 1.258).
\end{abstract}

SUmaRIo: I. El valor constitutivo del número agustiniano-II. Dinamismo platónico y estatismo aristotéliico.-III. El itinerario agustiniano de los números.IV. La constante " $h$ " aplicabile a la ontología moderna.-V. Relación de los números con su origen divino.

1.-EL VAlor constitutivo DEL NÚmERo agustiniano.

En las propiedades de los números encontró San Agustín un itinerario apto para guiar hacia Dios a las almas reflexivas. Claro está que para Agustín la palabra número suscita sonoridades y armonías que escapan completamente al ámbito de la atención ordinaria de los hombres. Veo un montón de libros. Los cuento: son siete. Este es su número. El número siete ha introducido para mí una suerte de unidad que me satisface más que el mero montón. Los tomo uno por uno y los coloco según sus proporciones y tamaños. El orden ha perfeccionado el número, y ahora me agradan más que cuando los hallé amontonados desordenadamente. Si un animal falto de razón hubiera pasado por allí, habría podido ver el mismo montón, pero no le hubiera preocupado ni el orden ni el número. Es lógico: le falta la razón. El número y el orden, que son capaces de introducir una proporción armoniosa entre elementos antes dispersos, son destellos razonables que se manifiestan en lo racional.

Dice San Agustín que el hombre no podría ordenar sus diversos conocimientos de las cosas, si se le apareciesen todas en confuso tropel, y sin haberlos señalado sus términos con números: sine quodam defixo termino: 
"Nada de esto podría hacer si la muchedumbre de las cosas se nos mostrase indefinidamente sin determinados términos fijos. Se advirtió en consecuencia, como sumamente urgente la necesidad de aplicar los números" 1.

Ya se ve que, cuando San Agustín habla de números, no se detiene en el obvio significado que tienen en su oficio de contar unidades. Se refiere principalmente a su papel ordenador de lo que sin él permanecería en confusión; y a su eficacia para hacer tender a las cosas hacia una unidad más o menos perfecta, componiendo armónicamente un todo con significación definida y propia, liberándolo de su estado de mera aglomeración caótica. Para él, siempre que haya elementos de algún modo concurrentes al logro de un fin o telos unitario, hay número:

"Y lo que no estando ordenado a un fin concreto, y sin embargo se desenvuelve razonablemente en medidas ordenadas, fue designado con el nombre de ritmo, que en latín sólo puede llamarse numerus" 2.

De este modo Agustín ve los números esparcidos por todo el Universo, estableciendo la racionabilidad, la inteligibilidad, el orden por todas partes, reduciéndose a la unidad los elementos dispersos y componiendo los acordes del himno universal. Esto que aquí veo es un árbol forque todas sus partes concurren ordenadamente a formar una unidad cerrada y completa: forman un número, no es un mero aglomerado. El árbol tiene una unidad interna que mantiene todas sus partes, desde ld raíz hasta los frutos, congregadas en una maravillosa unidad. A esta fuerza de cohesión o virtud unitaria interna San Agustín llama el viúmero del árbol. La semilla encierra un número, porque, en su pequeñez, contiene una potenciabilidad o eficacia suficiente, que en el tiempo oportuno ha de ir desarrollándose en movimientos concertados hasta que se completen, en un todo armonioso, las diversas partes que han de componer la planta. Lo mismo ocurre en un poema. Las sílabas largas y breves se ordenan convenientemente según números precisos, para obtener las medidas, que, ordenadas a su vez en ritmos o números más complejos, nos den el verso; y con los versos, se forma el poema. En el compás, siempre constante, que gobierna el movimiento de los astros se descubre el imperio de los números.

1 De Ord. II, 12, 35, PL. 32, 1012.

2 De Ord. II, 14, 40, PL. 32, 1014. 


\begin{abstract}
"En los movimientos rítmicos, y en cualquier modulación, comprendía que reinan los números y lo perfeccionan todo... Por las revoluciones constantísimas de los tiempos, por los cursos perfectamente calculados y definidos de los astros, por la cuenta perfecta de los períodos, entendió que todo lo dominan las medidas espaciales y los números" 3.
\end{abstract}

Ahora bien, ordenar es constituir: el número ordenador de los elementos esenciales que contiene un ente, y que lo ensambla en una unidad perfecta a su modo, le constituye en ser, ya que para ser, es preciso ser uno.

"El orden somete a una cierta conveniencia todo lo que ordena. No es otra cosa ser, que ser uno. Por lo tanto, cada cosa es en cuanto recibe en sí la unidad" 4.

Por eso, me parece que para San Agustín el número puro abstracto no basta. El número expresa el orden, la proporción debida, la armonía, $\mathrm{y}$ todo esto debe reinar sobre algo.

"Hacer (crear) se aplica a lo que deil todo no era; mientras que acondicionar (condere) significa ordenar lo que ya era de algún modo, para que sea más y mejor" 5 .

\title{
II.-Dinamismo platónico y estatTSMo aristotéLico.
}

¿Cuál es el verdadero significado atribuído por San Agustín al número, en orden a la constitución del ser? Sin duda San Agustín recibió esta doctrina de los números de los antiguos pitagóricos y platónicos. Desgraciadamente, casi todo lo que ha llegado hasta nosotros de semejantes teorías, proviene de Aristóteles, enemigo acérrimo de tales doctrinas, opuestas a sus propias teorías acerca del ser. Seguramente Aristóteles es fiel, en cuanto cabe, en lo que nos dice acerca de los números pitagóricos y platónicos; pero me parece que no se le hace injuria, si suponemos que dejó de comunicarnos muchas ideas de Platón sobre el modo y alcance de la intervención de los números en la ordenación del Universo.

En la indagación sobre el origen del mundo visible, Platón y Aris-

3 De Ord. II, 14, 41, y 42, PL. 32, 1014.

4. De Mor. Manich. II, 6, 8, PL. PL. 32, 1348.

5 De Mor. Manich. II, 7, 9, PL. 32, 1349. 
tóteles, tal vez todos los antiguos griegos, parten de una materia preexistente a todo lo demás, necesaria y eterna, pero carente de toda determinación. Nada podía decirse de ella. No era ser; sin embargo su destino consistía en servir de base originaria para cualquier ser. Platón pensó que era necesario introducir en ella números y proporciones adecuadas, imitando en lo posible ciertos arquetipos ejemplares, a fin de que fueran apareciendo los seres sensibles en toda su variedad. Mas para Aristóteles, estos números e ideas, entendidos como subsistentes en sí mismos por encima de la materia, además de exigir una explicación previa de sí mismos, que nadie podía dar, de nada servirían para resolver el problema de que se trata; o sea, explicar el origen y existencia de los seres que componen el Universo.

Según Aristóteles es la forma substancial la que opera el milagro, transformando en ser la indeterminada e inerte materia prima. La forma substancial aristotélica nunca tuvo existencia independiente propia; sin embargo, exhibe caracteres de permanencia eterna, a fin de ser capaz de servir como objeto verdadero de la ciencia: si ésta ha de merecer tal nombre, no ha de estar sujeta a lo que en verdad no es, pues sólo parece, o aparece ahora, para cambiar en el siguiente instante; sino que debe alimentarse de lo que necesariamente es. Ni forma ni materia separados son ser; pero tan pronto como se juntan, dan origen a un ser (sustancia).

El ser aristotélico aparece estático. Cuando algo se mueve en él, es que se está corrompiendo la materia: al aparecer otra forma, un nuevo ser ha sido generado. Aristóteles no percibe armonía alguna en el movimiento íntimo que preside la corrupción y generación de los seres. Ve, sí, la proporción: "Empédocles dice: "lo que constituye los huesos es la proporción". Ahora bien, éste es uno de nuestros principios, la forma propia, la esencia de cada objeto" (Met. I, 7). La proporción, como algo estático, está muy lejos del dinamismo de los números platónicos.

Si la elaboración del concepto de la esencia de los seres hubiera nacido bajo el signo de las proporciones, armonías y números platónicos, quizá se hubiera llegado a tener una representación del ser en estado dinámico, sin menoscabo de su necesaria e incomunicable individualidad y dotado de una permanencia adecuada. Y me parece que tales representaciones estarían conformes con las corrientes del pensamiento moderno. Desde luego, podrían encajar perfectamente, según creo, con la doctrina de Zubiri sobre la esencia.

Pero Platón emprendió la ímproba tarea, que necesariamente debía 
fracasar, de explicar el orden y belleza del Universo sensible mediante proporciones geométricas y números armónicos, aplicados a los cuatro elementos que la ciencia de su tiempo admitía comúnmente. La tierra, el agua, el aire y el fuego debían componerse a partir de triángulos geométricos de diversas proporciones, y combinarse luego según leyes matemáticas eternas, que obligasen a la materia, ciega de suyo, a ejecutar con algún orden sus movimientos y combinaciones, que habrían de resultar más bellas cuanto más se ajustasen a las proporciones exactas definidas por los números, y tanto más verdaderas cuanto mejor lograsen imitar la unidad', supremo origen del ser.

Evidentemente, Platón pedía demasiado a los números puramente matemáticos. No le fue difícil al frío raciocinio de Aristóteles cortar el vuelo de las pretensiones platónicas, demandando a su vez la razón de esa virtud todopoderosa de los números. Para Aristóteles, las teorías pitagórico-platónicas acerca de los números e ideas, en sí subsistentes, lejos de explicar satisfactoriamente el mundo sensible, introducen nuevas dificultades en el problema; pues es preciso primero, una explicación previa de esa eficacia ontológica de los números, que dista mucho de ser evidente de suyo; y después, su intervención como principio ejemplar y eficiente de los seres materiales y sus vicisitudes. La teoría de los números cayó profundamente en el descrédito para el pensamiento occidental.

\section{III.-EL ITINERARIO AGUSTINIANO DE LOS NÚMEROS.}

Sin embargo este resultado, inevitable por un lado, es también injusto. Porque es evidente para espíritus selectos y atentos, que en el Universo hay ecos, armonías y ritmos: números, en fin, que delatan por encima de la pesadez de la materia común, algo, una voz que nos invita hacia regiones donde lo que verdaderamente es, se manifiesta con perfiles más netos que los exhibidos en los comunes aconteceres de este mundo sensible. San Agustín es quizá el hombre postplatónico que más intensamente percibió estos ecos, como manifestación inequívoca del ser íntimo cie las cosas y como "signo" del hontanar primero de todo ser. Recogió lo más noble de las teorías antiguas, conjeturó la eficacia de los números que presiden la formación de los objetos, y estudió al fin la relación que existe entre los números y el alma que los percibe. Esos tres probiemas hallan en San Agustín un eco interesante. 
Por de pronto, descubre en el alma, o mejor en su conocimiento de las cosas, los mismos números que reinan en el Universo, pero más acendirados:

"Sintió que nada le agradaba sino la hermosura, y en la hermosura das figuras, en las figuras las dimensiones, en las dimensiones los números; y se preguntó si en la naturaleza se dan esa línea y esa redondez que hallamos en la inteligencia. Descubrió que es muy inferior, y que lo que ven los ojos no pueden compararse con lo que ve la mente" 6 .

San Agustín estudia esto en el libro Sobre la Música; ritmos y cadencias temporales de los sonidos, como elementos apropiados para componer cánticos y versos. Los números exhiben así la máxima pureza que podían alcanzar en aquel tiempo. Hoy es posible llegar mucho más lejos, al examinar los caracteres de la luz y de los colores.

San Agustín llama números sonantes a los que halla en el sonido físico; progresores, a los que aparecen en el acto del que pronuncia; occursores, a los que se producen en el oído del que escucha; recordabiles, a los que se dan en la memoria del que se vale de ella para recitar; judiciales, a otros más elevados, que residen en el juicio natural de nuestro sentir, cuando nos deleitan la igualdad y la cadencia del ritmo, o nos desagrada el desorden y aritmia ${ }^{7}$.

Pero se le atraviesa el problema de la interacción del cuerpo con el alma, de gran importancia para el problema que aquí ventilamos; San Agustín niega que el cuerpo pueda producir números en el alma, esto es, actuar como agente sobre un alma que haya de ser considerada como materia fabricable, y concluye:

"Los objetos corporales... producen algo, no en el alma, sino en el mismo cuerpo... Este mover el cuerrpo de diverso modo ¿no es un hacer más bien que un padecer?... Estas son las operaciones que realiza el alma, respondiendo a las pasiones antecedentes del cuerpo; unas la deleitan porque concuerdan con ella y otras la molestan porque tiene que oponerse. Y cuando padece algo en tales operaciones lo padece de sí misma, no del cuerpo, por tenerse que acomodar al cuerpo ${ }^{8}$. ¿Acaso podríamos subordinar el alma ail cuerpo, si es éste el que opera e impone números, si es él el que fabrica y ella es la materia con la que y de la que se fabrica un efecto numeroso? Si creemos eso, sin duda el alma es inferior al cuerpo" 9 .

6 De Ord. II, 15, 42, PL. 32, 1014.

7 De Mus. VI, 2-16, PL. 32, 1163-1172.

De Mus. VI, 5, 10, PL. 32, 1169.

De Mus. VI, 5, 8, PL. 32, 1168 . 
Concluye San Agustín que los números que aparecen en la sensibilidad son operaciones del alma, con ocasión de los corporales o sonantes, ya que el alma tiene sus propios números. La sensibilidad aprueba instintivamente una marcha, un canto o danza, llevados con orden y cadencia, o desaprueba lo incongruente; es que contiene en sí antecedentemente ciertos números judiciales sensibles, que la capacitan para aprobar o desaprobar. Así el alma racional percibe los números sensibles y los aprueba o reprueba porque tiene otros números aún superiores:

"La razón, que se sobrepone a esa delectación, de ningún modo podría juzgar los números que tiene blajo isu jurisdicción sin otros números más vivaces... Finalmente, atiende (la razón) qué es lo que obra el alma (cuya cabeza es esa misma razón) en moderar, operar, sentir y retener esos números; separar o esos números animales de los corporales; conoció que ella misma no habría podido advertir, distinguir o numerar con rectitud todo esto sin ciertos números propios y por eso antepuso esos números a todos los de orden inferior, por razón de esa estimativa judicial" 10.

Los números judiciales sensibles son imperfectos y en eso se diferencian de los racionales, que son exactos en sus medidas:

"Sigue pues investigando la razón, y pregunta a esa delectación carnal del alma, que se reservaba las funciones judiciales, si... son exactamente iguales dos sílabas breves, que acada de oír, o si puede ser que una de ellas sea algo más larga, aunque no llegue a la dongitud de una síllaba larga. ¿Quién podrá negar que eso es posible, ya que la delectación no percibe esa diferencia, y se deleita, como si dos sílablas desiguales fuesen iguales? ¿Pero hay error o desigualdad más torpe?... Y sin embargo no podemos negar que esa desigualdad resulta hermosa en su género y orden, en cuanto imita esa igualdad que no puede lalcanzar" 11.

Es pues grande la virtud de los números racionales: con su inalterable medida, gobiernan el ordien y belleza de cuanto hay de hermoso y ajustado o proporcionado en el mundo. Y puesto que esos números racionales residen en el alma, o mejor, puesto que pertenecen al alma como propios de ella, revelan la excelencia y perfección del alma:

"Todas las cosas le parecían (a la razón) numerosas; sin embargo, los números resplandecían más claramente en las dimensiones que en sí misma veía más exactas, cuando pensaba y cavilaba; las percibidas por los sentidos parecían más bien sombras y vestigios de aquéllas. Aquí se creyó

10 De Mus. VI, 10, 25, PL. 32, 1177.

11 De Mus. VI, 10, 28, PL. 32, 1179. 
grande y presumió sobremanera. Con tales pruebas osó declarar al alma inmortal. Lo discutió todo con diligencia y comprobó que su poder era grande y que ese poder se debía la los números. Le pareció estar en presencia de un cierto milagro y comenzó a sospechar que quizá era ella misma ese número con que todo se numera; o por lo menos que ese número debía encontrarse en aquella zona a la que ella (la razón) trataba de llegar" 12.

En efecto, ¿¿no podrá ser designado convenientemente con el título de razón ese número que todo lo compara y pesa, que preside el tribunal que juzga el orden y concierto de la Naturaleza?

"Esa investigación le persuadió de que la razón era ella misma, o era algo suyo propio, y que en esa razón nada había más poderoso que los números, o que el número no es ninguna cosa sino la razón" 13.

Esto escribía San Agustín en Casiciaco, recogiendo las doctrinas platónicas y mezclando la literatura con la filosofía, para poder sugerir que el alma podía ser un número "sempiterno y divino". Pero, al escribir el libro VI De Música había renunciado ya a tales platonismos literarios y se había centrado en la discusión cristiana del problema. ¿Dónde ve el alma los números?

"Nunca hubiera apetecido el alma aquella igualdad que descubríamos en los números sensibiles, y que no era cierta y permanente, sino sólo apuntada y fugitiva, si no la hubiese conocido en alguna parte... $i \mathrm{Y}$ dónde piensas?... Creo que allí donde haya una zona superior a los cuerpos; pero ignoro si será en el alma, o en otra zona superior al alma... ¿Admitiremos pues que los números transeúntes son producidos por otros permanentes? La razón me obliga a admitirlo" 14.

El hombre posee las artes y esas artes están presididas por los números racionales, que de suyo son estables y sempiternos. ¿Por qué entonces esas artes no son necesariamente permanentes en el alma? A veces las ignora, con dificultad las aprendle, con facilidad las olvida. Así, aunque los números son de suyo permanentes, cuando están en el alma no permanecen siempre en ella en una forma visible: aparecen y desaparecen con los cambios y vicisitudes a que está sujeto el hombre. Puede aprender y poseer esos números, mas para ello tiene que dirigir su atención hacia esa zona en que ellos permanecen y son eternos:

12 De Ord. II, 15, 43, PL, 32, 1014 s.

13 De Ord. II, 18, 48, PL. 32, 1017.

14 De Mus, VI, 12, 32, PL. 32, 1181 s. 
“ ¿Hacia dónde deberá moverse el ralma, para que se impriman en su mente aquellos números, produciendo en ella esa afección que llamamos ante? ¿Es que se los trasmite el que va interrogando con habilidad? $\mathrm{Me}$ parece que el alma sólo puede verificar eso en su propio interior, plara poder entender y responder que son verdaderas las cosas que le van preguntando... ¿Dime pues si esos números son mudables? -De ningún modo. ¿Y no habrá peligro de que nos engañe alguna desigualdad? -Nada me parece más seguro que dicha igualdad. ¿Pero de dónde puede venir al alma lo que es eterno e inmutable, sino del único eterno e inmutable, que es Dios? No veo que pueda creerse otra cosa" 15.

De este modo, auscultando las armonías del Universo, llega San Agustín al fin de su itinerario. Tomó el hilo de los números, que iba encontrando en la hermosura de las proporciones espaciales y de los ritmos y cadencias temporales; siguiendo su curso, entró en el hombre, atravesó su interior y subió hasta el seno de la Trinidad beatísima :

"El número comienza en la unidad, es hermoso por la igualdad o semejanza y se recoge en el orden. Por lo tanto, quien admite que toda naturaleza apetece la unidad para conseguir ser lo que es; y que se esfuerza en conservarse semejante a sí misma en lo posible: y que mantiene el orden propio en el espacio o en el tiempo, o en su propio cuerpo, produciendo la salud mediante un equilibrio conveniente, deberá confesar que todas las cosas que son y en cuanto son fueron hechas y constituídlas pox un Principio, mediante una Especie igual o semejante a Ei, y en las riquezas de su Bondad, en la que con una carísima caridad, por así decirlo, se reúnen el Uno y el que proviene del Uno" 16.

Volvamos ahora sobre nuestros pasos y recojamos la pregunta inicial. ¿Cuál es el auténtico significado atribuído por San Agustín al número, en orden a lo constitución del ser? Sin duda atribuye al número lo mejor y más poderoso, melius et potentius, que hay en las cosas: más aún, su propio ser:

"Contempla el cielo, la tierra y el mar, las cosas que arriba brillan, las que abajo reptan, nadan o vuelan: tienen formas porque tienen números; quítales la forma y no serán yla nada. Pues, ide dónde les viene el ser, sino de donde les viene el número, puesto que en tanto tienen ser, en cuanto numerosas?" 17.

A primera vista, parece que el número es la causa material de las

15 De Mus. VI, 12, 35, PL. 32, $1182 \mathrm{~s}$.

16 De Mus. VI, 17, 56, PL. 32, 1191.

17 De lib. arb. II, 16, 42, PL. 32, 1263. 
cosas. Pero excluye ese sentido deliberadamente: "tienen forma, porque tienen números, quítales las formas y nada serán". La fuente de la forma o del ser es la misma fuente del número. Para Platón el número es causa inmediata del ser, pues introduce un orden y proporción determinada en los elementos caóticos preexistentes e indeterminados, que no eran ninguna cosa de las que pueden nombrarse. El dios de Platón confería el orden desde fuera, obligando a los elementos a unirse formando un número armónico... Eso no vale para San Agustín, ya que es Dios el que crea los elementos iniciales. No existe ninguna materia tan indeterminada que sea innominable y sólo "perceptible para una especie de razonamiento bastardo", como dice Platón en el Timeo.

Para los griegos el ser sale del fondo del no ser: por eso llega después y es consecutivo: no es pues difícil concebir que los números confieren directamente el ser. En cambio, para San Agustín, los números son la revelación más clara de la intervención divina en el mundo: es el lenguaje del ser, cuando nos revela cómo lo va formando Dios. San Agustín percibió como nadie la maravilla de ese lenguaje que brota en todos los confines del Universo. Este, aunque modulado por tal muchedumbre de criaturas, forma un acorde tan armonioso, que nos llama hacia la eternidad.

Por lo tanto, el número no es el ser, sino revelación del ser; impronta del Creador en la criatura; el ser se hace visible al alma en el número, porque también ella fue creada por el mismo Creador y recibió las mismas huellas, aunque más excelentes. Por eso los acordes que vienen de abajo, resuenan en la lira del alma, prolongando una sonoridad que sube hacia arriba, y adquiere tonalidades divinas, ecos de eternidad.

IV.-La CONSTANTe "H" apLicable a la ontología moderna.

Intentemos rehacer el trabajo de San Agustín, aprovechando el material que la ciencia moderna pone a nuestra disposición, para analizar al pormenor la obra de Dios. Veamos, al efecto, un ser cualquiera, por ejemplo la sal común. Todos conocen perfectamente sus calidades físicas y sus propiedades culinarias. Podemos contar los gránulos que componen i.: porción de sal que tenemos delante; si nos resulta enojoso, porque son muchos, podemos medirla, o pesarla en una balanza: son 500 gramos. Esto nos basta para saber cuánto tenemos que pagar por ella, o 
hasta dónde podrá alcanzarnos para atender a las necesidades que prevemos. De ese modo vulgar, hemos aplicado los números en su más simple oficio de contar y medir; pero esto de poco nos sirve para llegar al conocimiento de la relación existente entre el número y el ser mismo del ente. En realidad, estos números sólo importan la unidad en su más lato sentido: el de un conglomerado, mero vestigio en el orden del ser. En lo dicho hemos hablado de la sal macroscópicamente, de un modo burdo, por decirlo así, y a bulto; de manera que resulta imposible mostrársenos en ella las delicadas finuras del ser.

Tratemos de superar con un análisis más atento el mero conglomerado que tan sólo llega a conseguir la unidad de un montón. Fijémonos en el elemento más pequeño que comporta todas las características de la sal. Esto no podía lograrse en tiempos de San Agustín; sin embargo, pueden aplicarse aquí las ideas que proclama San Agustín para el número en general. Este minúsculo elemento que entra indispensablemente en la sal es su molécula, que se compone de un átomo de cloro y un átomo de sodio. Este elemento molecular (y no sólo para la sal, sino para todos los cuerpos de la naturaleza), tiene características muy notables. Es uno. Aunque compuesto de otros dos subelementos, forma una unidad perfecta en su género, que le confiere una individualidad peculiar que puede exhibir frente a todas las demás individuales. $\mathrm{El}$ cloro y el sodio que, existiendo aparte, son también individuos perfectos en su género, al coadunarse para formar la sal, pierden en buena parte la individualidad que les era propia, en beneficio de la nueva que han contribuído a crear. En sus interacciones con los entes vecinos, ya no se enfrentan como cloro o como sodio; sino como sal común. Lo que no deja de ser admirable para el que atentamente lo considere; porque el cloro es un cuerpo gaseoso, de color amarillento, venenoso; y el sodio es un metal blanco como la plata, que es preciso conservar cuidadosamente al abrigo del aire, porque se oxidaría violentamente, ardiendo en su seno. Sin embargo, cuando esos elementos forman la sal común, se comportan de muy distinta manera, como es sabido. Ahora tienen otra individualidad: forman un ser distinto. Y es que el cloro y el sodio de la sal, no están meramente el uno junto al otro, como los elementos de un conglomerado cualquiera; sino que forman un verdadero sistema esencial, en sentido zubiriano. No son tan sólo dos elementos que están ahí para que un ente racional pueda contarlos desde fuera, asignándoles un número puramente matemático. Son ellos de por sí un verdadero número físico. Los dos átomos, 
uno de cloro y otro de sodio, presididos por su propia fuerza, se han ordenado en un sistema unitario y concluso: cloro para el sodio y sodio para el cloro, en unidad ontológica: la sal común.

Puede, pues, decirse para la sal: "no es otra cosa ser, que ser uno" y también: "las cosas que no son simples, imitan parcialmente la unidad con la concordia (de sus elementos), y en tanto son, en cuanto la consiguen" ${ }^{18}$. Tan pronto como el cloro y el sodio se disocian, la entidad sal queda aniquilada. "El ordien empuja hacia el ser, el desorden hacia el no ser" ${ }^{19}$.

Pero la unidad sal dista mucho de ser perfecta sin restricciones. Puede romperse con relativa facilidad, y sus elementos cloro y sodio persisten. La sal, en efecto, ni siquiera es un ente primario, de los que hace el Creador directamente. La sal se constituye a partir de otras criaturas, que le sirven de materia primera, y mediante sus virtudes le comunican, con el juego de sus fuerzas, la forma substancial que le es propia: su ser. Tienen pues ellos ser antecedentemente, y sin duda, más perfecto; por cuanto exhiben la unidad con más eficacia.

Existe, en efecto, el sodia libremente después de la ruptura de su unión con el cloro. Debe tener también su número unificante. Efectivamente los hábiles experimentos modernos han averiguado que el átomo de sodio consta de I 3 neutrones y II protones, que apiñados en su núcleo central, forman una unidad casi indestructible. Formando una corona móvil en su contorno, acompañan a este núcleo ir electrones con unión más floja, pero firme. Para que haya un átomo de sodio es preciso que todos esos elementos estén ordenados con precisión en un sistema unitario, en todo semejante al de la sal común, sólo que mucho más sólido y permanente. De nuevo tenemos aquí algo que es una determinada cosa, sodio, porque un conjunto de elementos que nada representarían en orden al sodio, si estuvieran dispersos, se han reunido en proporciones bien precisas y gracias a fuerzas internas perfectamente combinadas, formando un sistema unitario concluyente, que es su número, el cual hace que sea un ser determinado para nosotros: le da su ser físico, es su esencia.

Y aquí, lo mismo que en el caso de la sal, si los elementos dél sodio son disgregados, porque el átomo que formaba ha sido sometido a la fuerza brutal de algún poderoso ciclotrón, entonces no nos queda nada

18 De Mor. Manich. II, 6, 8, PL. 32, 1348.

19 Ibid. 
de sodio. Los residuos ya no son sodio, porque ya no ostentan el número y las proporciones que daban el ser al sodio. Son protones, neutrones, electrones, que tal vez se han combinado de nuevo en proporciones diversas, formando otros sistemas unitarios; pero estos ya no serán sodio. Se ha deshecho su número.

Y así llegan a la existencia los entes secundarios, los que tienen en su bàse otros entes más simples, más vecinos a la unidad perfecta. Se comprende que en fuerza de divisiones y subdivisiones habremos de llegar pronto al ente primario, a aquel cuyo sistema esencial unitario no conste de otros entes que puedan subsistir por separado, le sirvan de materia primera antecedente, y le presten con sus virtudes intrínsecas la forma substancial: virtudes intrínsecas no tanto del ente formado como de los entes conformantes. Las notas del ente primario han de formar un sistema tan cerrado y unido, que sólo puedan subsistir siendo ias unas para las otras, jamás por separado. Será tan perfecto su acorde que no haya fuerza creada que le pueda romper. Es preciso que tal entidad con todas sus características salga directamente de las manos del Creador.

Yo creo que el ente primario, materia primera de todos los entes materiales es ese agente minúsculo, que tanta importancia tiene en la ciencia moderna; hasta el presente, se ha revelado como unidad totalmente irreductible e indisoluble, y lo llamamos electrón. Dios creó toda la inmensa muchedumbre de electrones que hay en el mundo; los cuales, distribuyéndose armónicamente en proporciones variadísimas, van prestando por todo el ámbito del Universo sensible el número adecuado para que cada entidad material tenga la esencia pertinente, y module sus ritmos apropiados, y contribuya a entonar el himno de la creación.

Y ¿cuál será el número de esta entidad primigenia? Su unidad, por sólida e indestructible que aparezca, debe tener componentes, pues de otra suerte sería el Uno absoluto, no sería criatura. En efecto, el electrón tiene un sistema esencial rigurosamente unitario, indestructible frente a cualquier fuerza creada, cuyas notas, que sólo pueden existir en su sistema o estado constructo, son: fuerza-espacio-tiempo. Su número es perfecto puesto que forma una unidad acabada en su línea; sus elementos no pueden separarse, ni podrán subsistir aislados; unidad permanente, y sin embargo en perpetuo fieri, puesto que la virtud de su fuerza está en acción continua.

Es un ente material, el ínfimo en la jerarquía de los seres; sin em- 
bargo, al crearlo Dios, no salió de las manos divinas una criatura inerte, torpe y fría, inactiva y sin bríos. Es, si se quiere, de ínfima calidad, y por eso se debate en continuo esfuerzo, desarrollándose a lo ancho en el espacio, y a lo profundo en el tiempo; en perpetua agonía contra la nada, a la que vence siempre por ser acción del verbo substantivo a las órdenes del Creador.

Sin duda el lector exige aquí pruebas y aclaraciones de estas cosas que vamos diciendo. En efecto, existen tales aclaraciones y pruebas, que son el objeto de un libro todavía inédito; pero es imposible aducirlas aquí, donde por necesidad tenemos que darlas por supuestas. Podemos, no obstante, decir que tales pruebas surgen al analizar convenientemente lo que podríamos llamar los arpegios de la luz; o como dicen los científicos, el espectro luminoso. Así como el sonido con sus armonías proporcionó a San Agustín los elementos que necesitaba para seguir el curso de los números, del mismo modo, y con eficacia mucho mayor de suyo, la luz lleva en su manto de colores armonías delicadísimas, que silabean con mucha mayor nitidez que los sonidos, el lenguaje con que los números pugnan por contarnos cómo es la esencia del ente material en cuyo seno brota la luz.

Por lo poco que hemos dicho sobre la esencia o número del ente primario, y la de los entes secundarios, se echa de ver la gran diferencia que hay entre ellas, que no es sólo de grado. Esto indica que, al tratar de comprender algo del fondo de las cosas, necesitamos considerar dos aspectos que me agradaría designar con los nombres de vertiente o faz interna, y vertiente o faz externa del ente. La vertiente interna se encuentra allí donde se realiza el secreto del ser; es su esencia substantiva. La vertiente externa es todo el campo de las operaciones del ser, donde él sale a dar y recibir mediante toda la gama cuasi infinita de interacciones que intercambia con los demás seres. La luz es el resultado de tales operaciones externas del electrón, cuando trabaja en su máxima simplicidad e independencia posible. El electrón, en sus circunstancias apropiadas, se pone a desgranar fotones de variadísimas dimensiones; pero siguiendo siempre leyes numéricas centradas sobre una maravillosa unidad.

Los fotones tienen una propiedad increíble: conservan su individualidad durante toda su esencia. Tejen entre todos el manto de la luz; pero no coalescen. No se confunden entre sí formando a modo de masa común indescernible. Hijos uno a uno de la operación individual de cada elec- 
trón, conservan su autonomía al presentársenos para que hagamos en ellos nuestras observaciones. Por eso es posible adivinar en ellos con suficiente nitidez la silueta interna del ente material primigenio, en la que se destacan las tres notas de su sistema esencial a saber: fuerza espacio - tiempo.

Si nos ponemos a considerar atentamente lo que pasa en el Universo, nos daremos cuenta de que en él dominan tres constantes: peso, número y medida. El peso empuja por doquier para que cada cosa ocupe su puesto y cumpla su destino; el número computa y ordena los aconteceres en el tiempo, y los individuos en el espacio; la medida reparte en proporciones adecuadas las magnitudes espaciales y temporales. Son fuerzas inmensas para llevar a cabo los ingentes quehaceres de la Naturaleza. Son espacios y tiempo infinitos, para ordenar en ellos, en adecuadas formas y en rítmicos movimientos, la inmensa variedad de entidades, heterogéneas a primera vista, según medidas convenientes y armoniosas.

De siempre estas tres notas, fuerza-espacio-tiempo, se han destacado en la lira de la inteligencia humana por encima del concierto universal de los fenómenos sensibles. Debemos confesar que, si bien ellas se presentan en todas las operaciones de los entes macroscópicos, siempre suenan como algo confuso e inexplicable. Nuestra inteligencia debe enfrentarse constantemente con la fuerza, el espacio y el tiempo, y constantemente queda insatisfecha en el confrontamiento. Descartes declara a la fuerza como algo impensable, idea irremediablemente confusa. Newton, que la siente irresistiblemente en la ordenación de los astros, no se atreve a decir más que "los cuerpos se atraen, como si entre ellos actuara una fuerza". No puede explicarse ni explicarnos cómo puede ser una fuerza que actúa a distancia. Eddington declara que la fuerza es un duende que está siempre donde no se le busca. San Agustín nos asegura que si nadie le pregunta por el tiempo, le parece saber qué es; pero en cuanto trata de definirlo, se da cuenta de que lo ignora. Y la idea del espacio absoluto, ¿en cuántas confusiones no ha sumido a los sabios?

Es evidente que, en el concierto universal de los hechos naturales del mundo macroscópico, las tres notas, aunque inevitables, resultain siempre confusas e imprecisas. Pero si nos inmergimos en el mundo de los hechos microscópicos, sus tonos adquieren matices sorprendentes más claros y precisos. Si queremos comparar con la música las armonías del Universo, diríamos que las tres notas de que hablamos, de ruidos 
broncos y poco discernibles, se convierten en sonidos musicales; y lo que es más admirable, se conjugan en un acorde maravilloso que sólo el Creador Omnipotente es capaz de combinar.

Cuando en el mundo macroscópico se habla de energía mecánica, los sabios la entienden como una suerte de combinación de fuerzaespacio, sin hacer mención del tiempo. Pero una entidad en la que el tiempo no cuenta, se queda yerta y petrificada en el mundo de la materia. ¿Y no es esto algo insoportablemente contradictorio con la noción misma de energía? Pero en el mundo microscópico los hechos no soportan que el tiempo sea excluído del fenómeno energético. En el mundo macroscópico los hechos se presentan demasiado confusos y en tropel, para que podamos discernir en ellos con suficiente claridad la naturaleza de la fuente de donde manan, y al propio tiempo su propia naturaleza. Pero en el campo microscópico todo cambia de aspecto, no porque la naturaleza de los entes cambie; sino porque en el campo macroscópico intervienen muchos entes a la vez; en cambio en el microscópico, son responsables de cada hecho pocos entes, o quizá, uno sólo. Gracias a esta circunstancia los hechos presentan perfiles más netos; y por lo mismo, reflejan más claramente la naturaleza de su origen; es decir, la fisonomía de la vertiente interna del ente que los produce.

Esta es la causa por la cual, cuando examinamos bien la energía de una sola onda radiante, no podemos entenderla del todo, si no es ligada armónicamente con el tiempo, y acusando contornos precisos. Pero no es esto lo más sorprendente, con serlo tanto. La maravilla que ha dejado a los sabios, no atónitos, sino aturdidos, pues no acaban aún de comprenderlo, es que todas las ondas radiantes con sus correspondientes cargas energéticas, desde las de frecuencia más baja en el dominio de la radiotelegrafía, hasta las frecuencias más altas en los rayos cósmicos, pasando por los rayos caloríficos, luminosos y los rayos $\mathrm{X}$, en su inmensa variedad, tienen la misma fisonomía y acusan el mismo origen. Son fenómenos distintos entre sí, que atentamente considerädos, parecen operaciones diversas producidas por el mismo ente, o por entes que tienen exactamente la misma faz interna. Son todas distintas; pero la fuerza, el espacio y el tiempo se combinan en ellas de tal modo, que producen siempre el mismo acorde. Es el acorde que le fue dado percibir aislado por vez primera al sabio eminente Max Planck. La designó con el nombre de la constante " $h$ ", cuyo valor él determinó, y que tiene las dimensiones de fuerza-espacio- tiempo. No es un raro coeficiente matemático, 
como es tratado de ordinario, mediante el cual se logra expresar el orden que existe en el mundo de las radiaciones electro-magnéticas. Es mucho más que eso. Es la expresión de la naturaleza de un ente físico. Con su eficacia para introducir el orden en los acontecimientos de la vertiente externa del ente material, desperdigados de suyo e inconnexos, nos señala inequívocamente al ente que desde la sede permanente de su vertiente interna, los va produciendo. Si hay relaciones admirables entre los granos de energía o fotones que transportan las ondas electromagnéticas, es porque tales granos y tales ondas son el producto de las actividades externas de un ente que, si bien cambia sin cesar y de infinitos modos sus interacciones en el campo externo, conserva imperturbable su acción constitutiva interna, la que le da su ser y constituye su esencia.

La constante " $h$ " que exhibe las dimensiones características de la acción mecánica, ostenta en su constancia el rasgo esencial de permanencia que debe tener cualquier ente. Es sin duda la sombra siluetada de un ente. ¿De qué ente se tratará? Planck la entrevió, al percibir el crden entre la caótica bruma de la energía cuando emana de un horno; pero decía cosas tan desacostumbradas e inauditas, que los sabios, por lo común, ni las entendieron ni las creyeron. Ocurría esto al comenzar el presente siglo.

Volvió a decir su palabra la constante " $h$ " traducida esta vez por Einstein en su famosa ecuación que relaciona la energía radiante con la frecuencia de la onda irradiada. Con ella explicó en rgo5 el llamado efecto fotoeléctrico, en el que los electrones, aparecidos en el campo de la Ciencia poco antes que la constante " $h$ ", ejecutan acciones características muy notables. Los sabios siguieron sin comprenderla; pero comenzaron a barruntar su importancia.

Algunos años después un sabio más atento empezó a comprender lo que la misma constante " $h$ " decía sobre el maravilloso mundo de los espectros luminosos, estudiados con mucho empeño por los sabios desde hacía más de un siglo. Niels Bohr explicó satisfactoriamente en 19r3, gracias a lo que la constante " $h$ " le decía, el enigma entrañado en los espectros de la luz, que muchos habían querido forzar sin conseguirlo.

Es curioso observar que también en los espectros de la luz desempeñan un papel decisivo los electrones. Donde quiera que aparezca la famosa constante, allí están los electrones como elementos necesarios. En el espectro luminoso, lo mismo que en calor irradiado por el horno cstudiado por Planck, las ondas luminosas que los originan se engendran 
en el seno del átomo, merced precisamente a los electrones semisueltos que hay en él. ¿No será justamente el electrón el ente material, cuya csencia íntima reproduce en silueta la constante " $h$ "?

Los electrones, cargas eléctricas diminutas, son conocidos y analizados por sus atracciones y repulsiones características, así como por sus innumerables actuaciones que forman la extensa rama de la electrónica, pero en todas esas manifestaciones, aunque intervienen los electrones en estado puro, por decirlo así, se nos presentan en grandes muchedumbres y en tropel. En cambio, cuando fabrican las ondas luminosas dentro del átomo, actúan uno por uno. Cada onda simple es la acción de un electrón. Por eso su entidad interna se refleja claramente en las ondas, y. se puede reconocer en ellas la maravillosa silueta de la constante "h", que tio es otra cosa que el electrón mismo. La constante "h" es la expresión física del significado óntico del electrón. Nos dice qué es, qué se hace en el ente material que llamamos electrón, cuando sobre él recae y en él se mueve la acción del verbo ver.

El electrón es un ente material, cuya esencia (la acción de su verbo ser) consiste en una acción mecánica. Los momentos que forman su sistema esencial son : fuerza mecánica, espacio y tiempo; y sus contornos están delineados físicamente por la constante " $h$ ".

Al identificar el electrón con esta constante, se siente la impresión de que el enigma ha entregado su secreto. Una viva claridad, que se enciende en la misma vertiente interna del ente material, ilumina para nosotros con nuevas luces todo el escenario de la Naturaleza sensible. Fuerza - espacio - tiempo, que nos fatigan jugando con nosotros, mostrándose y ocultándose entre la turba caliginosa de los fenómenos inciertos, se nos muestran de pronto unidos en el acorde perfecto y claro que satisface plenamente a nuestro espíritu. Fuerza, espacio, tiempo son las tres notas bien concordadas que instituyen la esencia del electrón. No vamos a repetir ahora lo dicho en otro libro que es la base de todos nuestros razonamientos, pero sí parece oportuno extendernos en algunas consideraciones más.

El electrón es para nosotros el ente primigenio de todo el Universo material. Como tal, tiene caracteres especiales que le distinguen de todos las demás cosas materiales. El electrón se nos ofrece en su simplicísimo nacimiento originario (en gran muchedumbre, por supuesto), anterior a cualquier otro espécimen material. Después vendrán los elementos químicos, ordenados en sistemas armónicos, que en último análisis se resuel- 
ven en electrones, de los que habían recibido materia y forma. Más tarde se van colocando por orden de composición más complicada cada vez, todos los cuerpos que afectan a nuestros sentidos y que no exhiben notas de más alta jerarquía que las halladas taxativamente en el electrón. Es evidente que la naturaleza de torlas estas entidades depende de más cerca o de más lejos, de la naturaleza del ente primigenio de que constan; pero dada la complicación de sistemas, combinaciones y conglomerados que intervienen sucesivamente en su formación, es inevitable que la imagen del ente originario de que proceden, ha de hacerse en ellos menos recognoscible; y por lo mismo, es seguro que las acciones externas de todos estos entes materiales, mediante los cuales nosotros podemos acercarnos a las intimidades de la materia para ver lo que es, se nos han de presentar cada vez más confusas en orden a la manifestación de su naturaleza interna. Es por consiguiente necesario, a fin de conseguir una visión aceptable de lo que es y representa el mundo de la materia, que nos fijemos en sus entes originarios; bien persuadidos de que los caracteres y propiedades que en ellos encontremos, han de trasladarse convenientemente a todos sus productos ulteriores. Además, ya nos hemos convencido plenamente de que, si en algún punto ha de encontrar ruestra inteligencia la entrada a los secretos del ser, esto debe ocurrir únicamente en los dominios de la acción del ente primigenio cuando obra aisladamente, y no en sus operaciones de conjuntos más o menos confusos.

Decíamos, pues, que cuando el electrón opera en su pura simplicidad originaria, nos revela una acción integrada en las tres notas fuerzaespacio - tiempo, que forman en conjunto la famosa constante de Planck. $\mathrm{Si}$, como decían los antiguos, Operatio sequitur esse, podemos preguntarnos en vista de semejante obra: ¿qué es el electrón? ¿Qué hace cuando es? ¿En qué consiste la acción propia de su ser, de su verbo ser? Consiste en una fuerza, realiza una fuerza, que por su naturaleza se desarrolla en espacio y en tiempo. Es la fuerza espacio-temporal, cuyos, ecos pueden escucharse en todos los ámbitos del Universo. Nuestros sentidos oyen esos ecos sin entenderlos bien; pero nuestra inteligencia, al considerarlos en el lugar preciso de su nacimiento, comienza a comprender. Ya no será el tiempo una entidad independiente, ejerciendo un imperio tiránico sobre sus hijos, para acabar destruyéndolos; ni el espacio escenario vacío, o cuerpo inerte; ni vagará la fuerza como sombra inane condenada a estar siempre lejos de sus actos. No son partes que hayan 
concurrido desde lejos para confederarse, sino momento primigenios de la materia originaria. No son separables, porque la esencia o razón de ser de cada una se compenetra en las tres.

Desde los tiempos más remotos ha preguntado el hombre por el ser. Es la piedra, es el árbol, es el fruto, es el hombre. ¿Qué es eso que brota de todas las cosas, que al parecer permanece idéntico, aun siendo tan diferentes las cosas a que se aplica? ¿Qué es ser en general? ¿Qué significa ese ser, que está como suspendido sobre todos los entes? Alguien dijo que ese ser en general, carente de cualquier determinación concreta, coincide con la nada. La nada es también ausencia pura de toda posible determinación. Otro dijo: "la pregunta que eternamente se formula: ¿qué es el ser? Viene a reducirse a ésta: ¿qué es la substancia?" ${ }^{20}$. No intento analizar ahora, ni menos criticar, lo que otros han dicho al respecto. Sólo quiero indicar aquí que, a mi parecer, puede decirse con toda propiedad que el ser del ente-materia en general es una acción mecánica característica, exclusivamente propia de todos los entes materiales. Es una fuerza cuya virtud y actividad sólo puede desarrollarse en extensión local geométrica, y en sucesión temporal fluente. $\mathrm{El}$ espacio como extensión local, sólo significa algo, en cuanto es un modo natural de la virtud de dicha fuerza; y la fluencia temporal no es otra cosa que la expresión de su impotencia para instalarse definitivamente en el ser.

Cuando decimos que el electrón es una acción interna que consiste en fuerza-espacio - tiempo, afirmamos que en él se está realizando una acción especial del verbo ser. La acción de este verbo es peculiar; sin embargo se cumplen en ella algunas propiedades de las acciones de los ctros verbos. En la acción del verbo ser pueden considerarse dos extremos: el que mira al origen de la misma, y el que se dirige a su término. Es peculiar esta acción, porque a diferencia de las acciones de los otros verbos, que siempre se consuman en la vertiente externa de los entes que les dan origen, la del verbo ser es una acción que se produce en la vertiente interna sustantivando al ente. $Y$ en ella es dado considerar, como cn la de cualquier otro verbo, quién sustantiva y qué es lo sustantivado

Nuestra inteligencia resulta al pronto deslumbrada ante el fulgor mismo de la pregunta. El electrón es fuerza - espacio - tiempo. Parece que no hay otro sujeto de la acción de este es que el electrón mismo. Por otra parte, es claro que lo sustantivado por este es, no es otra cosa que

20. Arist. Metaph. VII. 
el propio electrón. El electrón es lo traído a la existencia y constituído en virtud de este es. Es evidente que el electrón, ente material, que lo mismo puede existir que no existir, carece de la virtud suficiente para mover de antemano, antes de su existencia, la acción de su propio ser. Con absoluta certeza debemos afirmar que la acción del ser que le constituye es movida por otro. El ser general es una actividad constituyente; y ser en particular es una acción constituída. Ser es una actividad originaria que no admite intermediarios entre el principio activo y el término también activo, por lo menos en parte. Si los dos extremos se identifican, la actividad es purísima y el ser perfectísimo. Si el término no es perfecto, necesita ser causado; o sea, su ser debe ser movido por otro; porque sólo la actividad purísima es capaz de mover el ser primero u originario.

Es pues el electrón un ente primario en la materia, cuya actividad intrínseca le viene desde fuera; o más bien debemos decir con toda precisión, le llega por dentro de sí mismo, desde regiones misteriosas que están más allá de lo más íntimo y profundo de su ser. Una actividad de naturaleza desconocida mueve por dentro el ser del electrón; y este, a su vez, siendo, es también actividad capaz de salir hacia fuera, ejerciendo acciones e interacciones por el lado de su vertiente externa.

Vemos aquí cómo la actividad creadora produce un número originario, en cuanto es posible perfecto en el reino de la materia. Concurren en él con admirable unidad la fuerza, el espacio y el tiempo, produciendo un acorde maravilloso, que va resonando cada vez más extenso y confuso, al través de todos los entes del Universo. De entre todas las criaturas, que vibran a su influjo, sólo el espíritu humano, que mora en medio de la materia, puede recogerlo desvaído en las encrucijadas del mundo sensible, hacerlo retroceder hacia su origen, y reconocer en su manantial primero, no sin admiración y alegría, que sólo un Creador es capaz de modularlo. ¿No son estos los caminos que San Agustín tanto se complacía en recorrer?

V.-RELACIÓN DE LOS NÚMEROS CON SU ORIGEN DIVINO.

Volviendo ahora sobre nuestros pasos, recordemos con San Agustín que los números matemáticos reciben su nombre —su ser- solamente a partir de la unidad, del unum: 


\footnotetext{
"Te convencerás fácilmente de que no nos los han proporcionado los sentidos del cuerpo, si consideras que cualquier número recibe su nombre de las veces que entra en él la unidad" 21.
}

Del mismo modo, los números físicos, aquellos de quienes Agustín dice que reinan sobre todo, y lo dominan todo, se forman y reciben su ser a partir de la unidad; y no de una unidad cualquiera, sino de la que es el Uno absoluto y perfectísimo, aquel único principio, al que alude en el tratado de Música, VI, 56 . Esto es justamente lo que ha resultado del análisis particular que hemos hecho del ente material. Y no deja de ser admirable la concordancia que aquí podemos constatar, del pensamiento de San Agustín con los posibles derroteros modernos. El ser del ente material aparece como el efecto, el espacio y el tiempo en una unida 1 lo más perfecta posible en su línea. El agente de esta acción es el Creador, la Unidad perfectísima, existente en sí misma, que operando lejos de nuestras miradas, ya que no podemos ser sus testigos, confiere la medida precisa en su juego a la fuerza mecánica desenvolviéndose en el espacio tiempo, y con esto instituye la esencia interna del ente material, que empieza a participar del ser, conservando un vestigio de su origen. $Y$ no es algo inerte esta esencia, ni fuerza que se consume sin residuo en su vertiente interna. Por el contrario, está dotada de virtud suficiente como para salir hacia sus afueras en busca de sus semejantes, a dar y recibir. Es su pondus, su peso o fuerza de atracción hacia los demás entes, recibido del Creador con el mandato de que la ejercite constantemente para constituir la inmensa variadad de los entes secundarios: átomos, moléculas, toda clase de cuerpos químicos, todas las moles o masas grandes y pequeñas; cada cual con su nombre, con su número, medida y forma: esencias tanto menos perfectas cuanto más alejadas de la unidad primera, y tanto más hermosas cuanto con más nitidez brilla en ellas el número.

Fijémonos un instante en el electrón, ente primigenio de la materia. Tiene una medida precisa, configurada en conjunto por la constante " $h$ ", y perfectamente perfilada en los límites en que se mueve cada una de sus tres notas. Estas forman un número perfecto, tanto por su valor matemático, vestigio trinitario claro, como por el orden y obediencia con que concurren a la formación de una unidad, tanto más admirablemente estable, cuanto más rebeldes a la constancia se nos ofrecen las tres notas,

21 De lib. arb. II, 8, 22, PL, 32, 1252. 
al considerarlas una por una. ¡Cuántas armonías se presentan dentro de este sistema, fuerza-espacio-tiempo, perfectamente concluso y unitario! ¡Y cuánto pondus en su unión! Y podemos en seguida extender nuestra consideración a los entes secundarios, dispuestos en órdenes sucesivos, cada cual con su propia medida, su correspondiente número y su peso o fuerza atractiva que todo lo dirige a su destino. Todo lo cual sólo se explica satisfactoriamente buscando la razón en la virtud creadora.

"No es Dios esto, en el sentido que conocemos la medida en las cosas que medimos; y el número en las que contamos; y el peso en las que pesamos: más si entendemos aquel modo según el cual la medida fija. de antemano la magnitud de cualquier cosa, y el número confiere la hermosura a todas las cosas, y el peso lleva a todo, a su descanso y estabilidad, es todo esto en primer lugar, con toda verdad y sin multiplicidad alguna, Aquel que fija sus términos a todo, da su forma a todo, y lo ordena todo... Lo has dispuesto todo con medida, con número y con peso, como diciendo: de tal modo han sido dispuestas todas las cosas que tengan cada una su propia meidida, su propio número y su propio peso; todo lo cual irá cambiando al compás de da mutabilidad de cada cual, según su género, en aumentos y disminuciones; en muchedumbre o en escaso número; en ligereza o en gravedad" 22.

San Agustín llega a sospechar que la sabiduría y número, que campean inmutables por encima de nuestras mentes, en resumidas cuentas, se identifican; si bien pueden diferir en algún aspecto:

"La potencia según la cual abraza fuertemente desde un cabo a otro, tal vez puede llamarse número; y aquella mediante la cual lo dispone todo con suavidad, la llamaríamos propiamente sabiduría" 23.

Lo potencia de los números en efecto, se extiende sin restricción a todos los entes, tanto a los racionales como a los que son pura materia. La sabiduría sólo conviene a los racionales; pero, bien mirado, esta diferencia se encuentra sólo en el término, no en su origen. El origen de todo es aquella unidad perfectísima, que crea con diversos efectos: a unos les da tan sólo el pondus como fuerza ciega para que corran a unirse con sus semejantes a fin de que a costa de sí mismos (por eso son materia), formen números y esencias secundarias, según leyes definitivas e intransgredibles. A otras les da sabiduría: la fuerza, que brota de la que Dios puso en su esencia, su vertiente interna, es de más altos quilates,

22 De Gen. ad lit. IV, 7, 12, PL.

23 De lib. arb. II, 11, 30, PL. 32, 1258. 
porque resplandece en visión y amor. Visión, para que pueda contemplar la verdad eterna con su número divino; amor, para que salga a ejercitar sus virtudes en su vertiente externa, sin menoscabo de sí mismas (por eso son espíritu) y hagan obras, que resplandezcan con sus números bien concertados, a semejanza de los que ven en la luz inconmutable.

Se comprende perfectamente lo que tanta veces repite San Agustín: el hombre con sus malas obras se corrompe; sin embargo, siempre es mejor que el bruto. Lo es en su vertiente interna, obra exclusiva de Dios, donde brilla su imagen, su número. Pero las obras que el hombre ejecuta en su vertiente externa, son suyas y de su responsabilidad, ya que él las ejecuta a la luz de aquella sabiduría que Dios puso a su disposición y libre albedrío para que pueda usar de sus fuerzas a discreción, y se arredite con sus obras, que pueden ser hermosas o deformes, según que se ajusten bien o mal a los números y medidas sempiternos, que le es dado contemplar con claridad suficiente.

Estas obras no alterarán su íntima esencia. No son constitutivas; pero tal vez pueden ser constitucionales, por cuanto brotan de su esencia; cierto que hacia la vertiente extenna, pero al fin vertiente suya. Si son buenas, resonará en ellos cada vez más nítido el acorde perfecto, acercándole más y más a la unidad perfectísima. Y si son malas, su deformidad disolvente y aniquilante se refundirá en el alma de que proceden, obscureciendo más y más la imagen divina de su vertiente interna. Con razón dice San Agustín que, si el alma se aleja de Dios para entregarse a las criaturas, que están por debajo de sí misma, se biere a sí misma, se corrompe y degenera, rebajándose al par de los brutos.

Tenemos, pues, que la sabiduría es el número plasmado por el Creador en alma racional, para que contemplando la verdad, multiplique las acciones del bien. ¿Cómo es posible entonces que el hombre yerre tanto, mezclando las tinieblas con la luz, el bien con el mal?

Es en efecto el hombre una lira delicada capaz de recoger los acordes de la creación y armonizarlos de algún modo con el supremo acorde del Creador pero jcon cuántas deficiencias! No podemos contemplar sin sombras el número divino, ni siquiera podemos ver directamente el que Dios dejó impreso y brilla en la faz interna de nuestro propio espíritu. No podemos ser testigos de lo que Dios hace cuando nos hace y nos sigue haciendo, Gracias al las riquezas que Dios deposita en esta su obra, 
el hombre tiene virtud suficiente para contemplar las esencias; sin embargo, dado su estado actual, no le es dado llegar a ellas sino a través de los fenómenos filtrados por los sentidos. Parece como si el espíritu del hombre debiera tener ventanas abiertas hacia dentro, hacia las amplias regiones que deben de extenderse por el lado de su interior; y que por alguna razón oculta, están cerradas u opacas. ¡Parece una crisálida el espíritu del hombre!

San Agustín habla insistentemente de una iluminación interior. Evidentemente es necesaria; pero ¿en qué consiste? La luz nos viene del Creador. Pero ¿acaso directamente, por encima de sus obras, las criaturas? La virtud sensitiva que integra nuestro sistema sustantivo, es suficiente para convertir en luz esplendorosa los agentes que le envía el ente material. ¿Con qué esplendores se vestiría nuestro espíritu, si tuviera abiertas sus ventanas internas? Pero no sólo le está vedada la contempla. ción de otros entes espirituales: ni siquiera se ve a sí mismo directamente en su interna esencia, que es la acción divina con que Dios lo creó a semejanza surya. Solamente puede contemplar en su consciencia sus propias obras realizadas en el escenario medio interno del gran sistema bumano. Así como las operaciones del ente material se convierten allí en luz de los fenómenos, de la misma manera, las operaciones del espíritu son luz de las esencias. Esta es la causa que empuja sin descanso a nuestro espíritu a conocer esencias. Es el peso de su propio ser; sin embargo, siempre está insatisfecho con la visión de las esencias. La visión meramente sensitiva del bruto es perfecta para el bruto; la visión del hombre, aun siendo más elevada que la del bruto, es insuficiente para el hombre. El hombre siente, sin que pueda siquiera dudarlo, que tiene más poder de conocimiento del que se le ofrece en su visión. Por eso el bruto goza tranquilo de su vida sensitiva, mientras el hombre se echa a discurrir y cavilar, entre grandes solicitudes y cuidados, preguntándose siempre: ¿qué es ésto? Lo cual arguye que el hombre, en el orden dei conocimiento, puede más de lo que puede. Si pudiéramos conocer la verdad tan sólo a nuestra medida, eso nos bastaría.

¿Y cómo podríamos lograrlo? Una sola cosa sería suficiente. Ai tener conciencia de la luz que brota en la interacción de nuestro espíritu con los agentes materiales (que no es otra cosa que la acción externa del espíritu al concurrir, dignificándolas, con las acciones externas de los entes materiales), nos es dado contemplar inmensas maravillas. Pero, ¿qué sería, si se nos concediera ver de cara la dignidad de nuestro propio 
ser, si pudiéramos contemplar directamente la acción divina con que Dios nos hace? Parece como que veríamos algo de los dedos divinos, cuando acaban su obra, o como que sentiríamos el aliento divino, o como que contemplaríamos la imagen divina. En esa luz superior podríamos percibir y comprender todas estas cosas que Dios ha ido colocando en la esfera de nuestra influencia natural: las comprenderíamos sin trabajo, sin zozobra, sin angustia y sin error.

Ciertamente aún nos faltaría mucho para llegar a entrever la verdad absoluta, que está todavía más allá. Pero ya no sentiríamos, como San Agustín, esta miseria a la que nos condena la necesidad de enredarnos en la madeja de las sensaciones, para descubrir una verdad que es tanto más pura y amable, cuanto es más sencilla. Encontraríamos un cierto reposo y paz en este mundo. Pero aún necesitaríamos ser investidos del don divino, gratuito, que habría de elevar nuestra naturaleza a esferas más altas, a jerarquías más encumbradas. Gracias a ese don, podríamos ingresar en el círculo divino, en el que se contempla, no ya sólo la punta de los dedos divinos, o el aliento de su boca, sino el divino rostro, esa divina Faz que todo lo ilumina desde el alcázar supremo en que mora e] Uno, que es la Verdad y que es el Bien.

\section{P. Víctor Tuesta, O. S. A.}

\section{BIBLIOGRAFIA}

BeRdiatrf, N., Essai de Métaphysique eschatologique. Acte Createur et objectivation, Paris 1941.

ReRLINGER, R., Augustins dialogische Metaphysik, Frankfurt 1962.

Boussoulas, N.-I., L'Etre et la composition des mixtes dans le Philèbe de Platon, Paris 1952.

BrÉHIER, E., La Filosofía de Plotino, Buenos Aires 1953.

BRunner, F., Platonisme et Aristotelisme, Louvain 1965.

LIES, A., Definition de l'Etre et nature des Idées dans le Sophiste de Platon, 2. ${ }^{a}$ ed., Paris 1963.

Hartmann, N., Platos Logik des Seins, 2. ${ }^{a}$ ed., Berlin 1965.

Hellin, J., La analogía del ser y el conocimiento de Dios en Suárez, Madrid 1947. Hengstenberg, H.-E., Das Band zwischen Gott und Schöpfung, Regensburg 1948. Horfmann, E., Platonismus und christliche Philosophie, Stuttgart 1966.

HoLL, A., Seminalis ratio, Wien 1961.

K.ALIBA, Cl., Die Welt als Gleichnis des dreieinigen Gottes. Entwurf zu einer trinitatischen Ontologie, Salzburg 1952.

KöNIG, H., Das organische Denken Augustins, Paderborn 1966. 
LAVelle, L., De l'Etre, 2. ${ }^{\mathrm{a}}$ ed., Paris 1947.

I,ORENZ, R., "Fruitio Dei bei Augustinus": Zeitschrift für Kirchegeschichte 63 (1950-51) 57-132.

MaRITAin, J., Sept Leçons sur l'être et les premiers principes de la raison speculative, Paris (1932-1933), 3. ${ }^{\mathrm{a}}$ ed., Paris, sin fecha.

MARTíN, G., Klassische Ontologie der Zahl, Köln 1956.

IIC KEOUGH, M.-J., The Melaning of the rationes seminales in St. Augustine, Washington 1926.

MerLeaU-Ponty, Signes, Paris 1960.

Mertens, K., Das Verhältnis des Schönen zum Guten in der augustinischen Frühschriften, München 1940.

MüLler, E., Augustinslehre von Einheit und Dreieinheit, in ihrer Bedeutung für Sein und Erkennen, Erlangen 1929.

NinK, C., Ontologie. Versuch einer Grundlegung, Freiburg 1952.

Ricoevr, R., Platon et Aristote (Les cours de Sorbone. Tirado a multicopista).

RINTELen, Fr. J. von., "Deus Bonum omnis Boni. Augustinus und modernes Wertdenken”: Gragmann-Mausbach, Aurelius Augustinus, Köln 1930.

RollaNd DE RENÉville, J., L'Un-multiple et l'Atribution chez Platon et les Sophistes, Paris 1962.

SCHINDLER, A., Wort und Analogie in Augustins Trinitätslehre, Tübingen 1965.

SCHNeIDER, R., Seele und Sein. Ontologie bei Augustin und Aristoteles, Stuttgart 1957.

Schulten, W., Augustins Lehre vom "summe esse" und "esse creatum", Würzburg 1935.

ScraccA, M.-F., Acto y Ser, Bancelona 1961.

Trouillard, J., La Procession plotinienne, Paris 1955.

TschoLL, J., "Augustins Interesse für das körpperliche Schöne": Augustiniana 14 (1964) 72-104.

VeLEZ, P., "El Número Agustiniano": Religión y Cultura 15 (1931) 139-196.

VERBake, G., "Augustin et le Stoïcisme": Recherches Augustiniennes (1958) 67-89.

WÁgner, H., Existenz, Analogie und Dialectik, 2 vol., München-Basel 1953.

ZochER, R., Die philosophische Grundlehre. Eine Studie zur Kritik der Onotologie, Tübingen 1939.

ZuBIRI, X., Sobre la Esencia, Madrid 1963. 